\title{
ELECTRO-OCULOGRAPHY AS A FUNCTIONAL TEST IN PATHOLOGICAL CONDITIONS OF THE FUNDUS I. FIRST RESULTS*
}

BY

\section{J. FRANÇOIS, G. VERRIEST, AND A. De ROUCK \\ From the Ophthalmological Clinic of the University of Ghent Director: Prof. J. François}

THE modifications of the standing potential in pathological fundus conditions are practically unknown, although electro-oculography (EOG) is a technically simple and clinically very efficient method of obtaining an indirect estimate of its value. Although the EOG is now widely used in order to study ocular motility, it is generally not considered as a functional test: only Riggs (1954) has reported diminished deflections in a case of pigmentary degeneration, and we ourselves have studied the EOG in a few cases of congenital retinal abnormality, such as Oguchi's disease (François and Verriest, 1954) and total colour blindness (François, Verriest, and De Rouck, 1955b). The present paper deals with the technique, physiological values, and results obtained in a few cases of the more typical diseases of the choroid and the retina.

\section{Technique}

After a study of the regional differences of conductions on the face of one-eyed subjects (François and De Rouck, 1955), we adopted the following electrodescheme as giving the greatest amplitudes, the most constant regularity, and the most independent records for both eyes (Fig. 1):

(1) On the temporal orbital margin, a little below the external canthus of the right eye;

(2) On the base of the nose, near the internal canthus of the right eye;

(3) On the base of the nose, near the internal canthus of the left eye;

(4) On the temporal orbital margin, a little below the external canthus of the left eye.

(5) A mass-electrode is placed on the forehead or on the occiput.

We use non-polarizable silver electrodes, attached to the skin with collodion. The skin is cleaned with ether, and contact is aided with commercial electrode jelly. An ink-electroencephalograph is used for the registration.

The subject performs, as rapidly as possible, two ocular movements in an interrupted series:
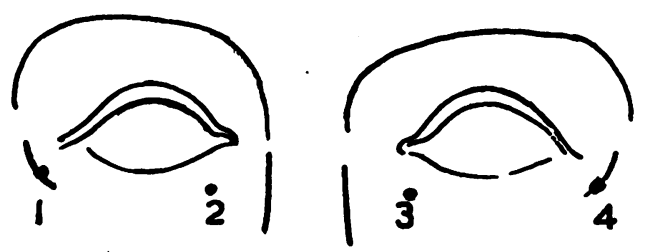

Fig. 1.-Scheme of arrangement of electrodes.

(i) from the extreme left to the extreme right (LR);

(ii) from the extreme right to the extreme left (RL).

* Received for publication August 5, 1955. 
The derivation $1 / 2$ gives the registration of the standing potential of the right eye and $4 / 3$ the same for the left eye (in cases of unilateral enucleation with or without implant or prosthesis, the corresponding derivation is nearly zero).

We have adopted for each eye (mean deflection) as the basis of estimating the value:

$$
M=\frac{L R+R L}{2}
$$

These measurements are effected in moderate brightness, without previous dark- or light-adaptation, to prevent a rapid modification of the values (François, Verriest, and De Rouck, 1955a).

\section{Physiological Values}

We recorded the EOG of both eyes in a series of 34 normal subjects. We also obtained 61 utilizable values of $M$; these form a normal distribution with a good approximation (Fig. 2). The arithmetical mean $m=405 \mu \mathrm{V}$ and the standard deviation $\sigma 60 \mu \mathrm{V}$. Theoretically 95.4 per cent. of the normal values must be between $m \pm 2 \sigma$, or 285 and $525 \mu \mathrm{V}$. In one subject we obtained very low values $(M=130 \mu \mathrm{V}$ for the right eye and $215 \mu \mathrm{V}$ for the left eye). According to Chauvenet's criterion, we did not include this case in the statistics.

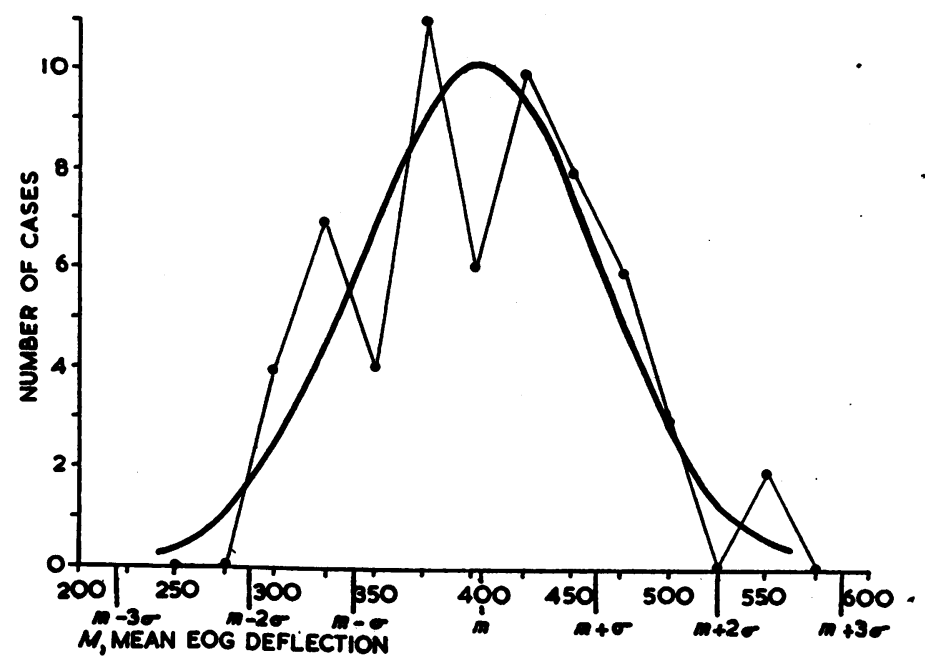

FIG. 2.-Physiological values of $M$.

We compared the values of the two eyes in 28 subjects and established that in normal conditions (Fig. 3, overleaf):

$$
\frac{M_{\max }-M_{\min }}{M_{\max }} \ll 0.33
$$

\section{Pathological Eye-Conditions}

(1) Microphthalmos.-We examined two cases. In the first the condition was bilateral and the values of $M$ very low (right eye $115 \mu \mathrm{V}$; left eye $55 \mu \mathrm{V}$ ). 


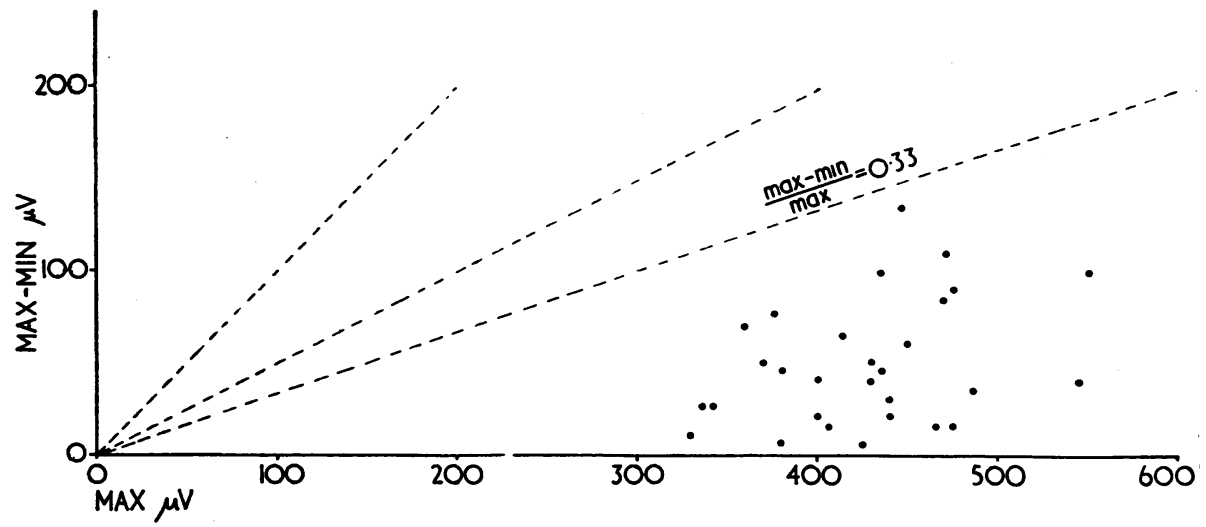

Fig. 3.-Comparison between values for two eyes in normal subjects.

In the second the condition was unilateral and complicated by a coloboma of the optic nerve and the choroid; on the affected side the EOG was markedly reduced $(270 \mu \mathrm{V})$ in comparison with that of the sound eye $(440 \mu \mathrm{V})$.

(2) Congenital Functional Abnormalities of the Retina.-We examined three cases of total colour blindness with amblyopia (" rod-monochromatism "). In .one we obtained very high normal values (right eye $500 \mu \mathrm{V}$, left eye $450 \mu \mathrm{V})$; in the second lower, but normal, values $(300 \mu \mathrm{V}$ for both eyes); in the third we also obtained normal values, but these were not comparable, because we were using a different technique.

We also obtained normal values in a case of protanopia (right eye $425 \mu \mathrm{V}$; left eye $480 \mu \mathrm{V})$, in a case of pronounced protanomaly $(400 \mu \mathrm{V}$, quotient of anomaly $0 \cdot 16$; marked depression of the spectral sensitivity in the red), and in cases of deuteranopia and deuteranomaly (quotient of anomaly 3.6).

A case of Oguchi's disease showed a normal EOG (440 and $425 \mu \mathrm{V})$.

However, in all these congenital abnormalities, there are no histological features indicating that the functionally absent receptors are missing.

(3) Tapeto-Retinal Degenerations.-Eight cases of primary pigmentary degeneration were tested:

Four showed pathologically low values: $140 \mu \mathrm{V}$ for both;

Right $100 \mu \mathrm{V}$, left $170 \mu \mathrm{V}$.;

$200 \mu \mathrm{V}$ for both;

Right $250 \mu \mathrm{V}$, left $200 \mu \mathrm{V}$.

Three gave a subnormal value for one eye: Right $270 \mu \mathrm{V}$, left $340 \mu \mathrm{V}$;

Right $245 \mu \mathrm{V}$, left $390 \mu \mathrm{V}$;

Right $285 \mu \mathrm{V}$, left $200 \mu \mathrm{V}$.

One gave high normal values: Right $500 \mu \mathrm{V}$, left $510 \mu \mathrm{V}$.

This last case was an initial one, with a monophasic dark-adaptation curve (final global threshold: $\log$ asb $0.05-2.00$ ) and an extinguished ERG as in the other cases. 
In a case of atrophia gyrata, a young girl with typical fundus modifications and myopia, mild concentric contraction of the visual fields, high monophasic dark-adaptation-curve (global threshold after $20 \mathrm{~min}$ : log asb $0.7-3.0$ ), and an abolished ERG, the values were $335 \mu \mathrm{V}$ for the right eye and $360 \mu \mathrm{V}$ for the left eye

In a case of abiotrophic juvenile macular degeneration, with normal ERG, objective and subjective CFF, and dark-adaptation curve, the values were again normal: $375 \mu \mathrm{V}$ right eye and $400 \mu \mathrm{V}$ left eye.

In a case of unilateral senile macular degeneration (retinitis disciformis) the result was $220 \mu \mathrm{V}$ on the affected side and $330 \mu \mathrm{V}$ on the sound side.

(4) Chorio-retinitis.-Among our cases of cicatricial diffuse or disseminated chorio-retinitis, two showed a normal EOG (the first had a normal and the second a diminished ERG), and three others gave pathological values. The first of these three cases had a bilateral, heavily pigmented, diffuse chorioretinitis with impairment of central vision, central and paracentral scotomata, a slightly subnormal dark-adaptation curve, and a subnormal $b$-wave in the ERG. The values of $M$ were right eye $50 \mu \mathrm{V}$, left eye $260 \mu \mathrm{V}$.

In the second case, the lesions were circumscribed at the posterior pole, the values of $M$ were $145 \mu \mathrm{V}$ in the right eye and $125 \mu \mathrm{V}$ in the left eye.

The third patient was a woman aged 42 years with very pigmented lesions, macular choroidal sclerosis, abolition of central vision in the right eye (left eye : $1 \cdot 0$ ), central and paracentral scotomata, a normal red-green colour-sense, a high biphasic retarded dark-adaptation curve with a subnormal final threshold (log asb $0 \cdot 6-5 \cdot 0$ ), a diminished ERG (amplitude of the $b$-wave with the apparatus of Karpe : $50 \mu \mathrm{V}$ ), and a reduced objective CFF. The values of $\mathrm{M}$ were $210 \mu \mathrm{V}$ in the right eye and $250 \mu \mathrm{V}$ in the left.

Two cases of toxoplasmic cicatricial central necrotizing chorio-retinitis had a normal EOG.

We examined a case of secondary pigmentary retinicis after measles. The EOG was at the inferior limit of the physiological range in the right eye $(265 \mu \mathrm{V})$ and gave a normal value in the left eye $(360 \mu \mathrm{V})$. This case presented in the beginning an extinguished ERG; one year later, there was an isolated negative deflection (P III). The visual fields presented an annular scotoma and there was a marked hemeralopia.

A case of retinitis septica, with healed secondary retinal detachment of the left eye, showed values of $330 \mu \mathrm{V}$ in the right eye and $140 \mu \mathrm{V}$ in the left eye. The ERG was absent in both eyes.

(5) Myopia Gravis and Myopigenic Retinal Detachment.-In four cases of high myopia with pronounced choroidosis the values of the EOG were normal ( 470 and $450 \mu \mathrm{V} ; 335 \mu \mathrm{V} ; 400$ and $500 \mu \mathrm{V}$; 490 and $420 \mu \mathrm{V}$ ).

Five eyes with actual or old, unhealed total detachment showed very low pathological values $(145 \mu \mathrm{V} ; 50 \mu \mathrm{V} ; 50 \mu \mathrm{V} ; 170 \mu \mathrm{V} ; 250 \mu \mathrm{V})$. 
Two cases of healed detachment were examined. The first (Fig. 4) showed a diminished value $(200 \mu \mathrm{V} ; 500 \mu \mathrm{V}$ for the sound eye), and the second showed normal values $(470 \mu \mathrm{V})$ although the ERG was absent.

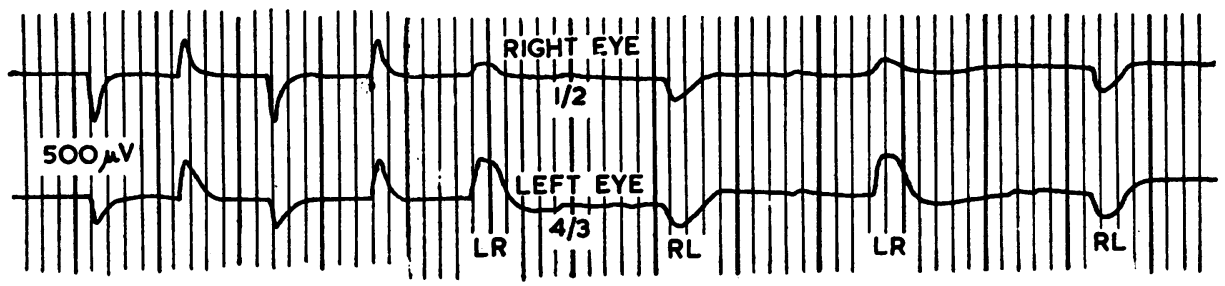

Fig. 4.-Pathological electro-oculogram in retinal detachment of the right eye. Value of $M$ : right $200 \mu \mathrm{V}$, left $500 \mu \mathrm{V}$.

(6) Vascular Disturbances. - We obtained normal values in cases of hypertensive retinopathy, diabetic retinopathy, embolism of the central artery, periphlebitis, pre-retinal haemorrhage, and diffuse choroidal sclerosis.

(7) Glaucoma.-We also obtained normal values in cases of wide-angle, narrow-angle, and traumatic glaucoma. In a case of congenital glaucoma we found a subnormal value in one eye $(210 \mu \mathrm{V})$, and in another case a normal value $(470 \mu \mathrm{V})$, the other eye being enucleated.

A patient with very advanced wide-angle glaucoma, no visual perception in the right eye, and a thrombosis of the central vein with haemorrhagic glaucoma in the left eye gave the following results: right eye $160 \mu \mathrm{V}$, left eye $175 \mu \mathrm{V}$. The ERG was subnormal for both eyes and the dark-adaptation curve in the left eye highly pathological.

(8) Optic Nerve and Higher Optic Pathways. - We found normal values in cases of papillitis and retrobulbar neuritis, and in a case of cerebral thrombosis with homonymous triquadranopsia, acquired total colour blindness, deuteranopic anomalossopic findings, and normal spectral luminosity.

\section{Summary}

With a standard method, we used electro-oculography as an indirect estimation of the standing potential in conjunction with other functional tests in normal and pathological cases. The normal range $(m \pm 2 \sigma)$ of the mean deflection $M$ lies between 285 and $525 \mu \mathrm{V}$. Too low values were principally found in cases of microphthalmos, primary pigmentary degeneration, cicatricial chorio-retinitis, and retinal detachment. There is no direct correlation with the ERG, which seems to be more rapidly affected.

\section{REFERENCES}

FrançoIs, J., and DE RoucK, A. (1955), Bull. Soc. belge. Ophtal. (in the press).

- and Verriest, G. (1955). Ibid., No. 108, p. 465.

- $1955 \mathrm{~b})$. Bull. Soc. belge Ophtal. (in the press).

MARG, E. (1951). Arch. Ophthal. (Chicago), 45, 169.

Riggs, L. A. (1954). Amer. J. Ophthal., 38, no. 1, pt II, p. 70-78. 